\title{
Synthesis, crystal structure and catalytic oxidation studies of a new acid pyrophosphate metallate
}

\author{
N. Hamdi'1, S. Hidaoui' ${ }^{1}$ R. Benali Cherif², B. El Bali³ ${ }^{3}$ M. Lachkar1 \\ ${ }^{1}$ Engineering Laboratory of Organometallic and Molecular Materials (CNRST, URAC 19), Faculty of Sciences, University Sidi \\ Mohamed Ben Abdellah, Po. Box 1796 (Atlas), 30000 Fez, Morocco. \\ ${ }^{2}$ Abbes Laghrour University. 40000, Khenchela, Algeria \\ najlaa.hamdi@usmba.ac.ma
}

A new metal pyrophosphate, formulated as $\left[\left(\mathrm{H}_{2} \mathrm{O}\right)_{2} \mathrm{Co}_{2}\left(\mathrm{~N}_{2} \mathrm{H}_{5}\right)_{2}\left(\mathrm{HP}_{2} \mathrm{O}_{7}\right)_{2}\right]$ has been synthesized using wet chemistry and investigated by single crystal X-ray diffraction. The compound crystallizes in the triclinic system (S.G: $P)$ with the following parameters $\left(\AA,{ }^{\circ}\right)$ : $\mathrm{a}=7.2957(6), \mathrm{b}=$ 7.3932(4), $c=14.7194(8), \alpha=85.717(4), \beta=83.703(6), \gamma=79.710(5)$. The crystal packing consists of layers parallel to bc plane. These layers are joined by strong hydrogen bonds, building up a three-dimensional infinite network. The structural analysis was coupled with Hirshfeld surface analysis to evaluate the contribution of the different intermolecular interactions to the formation of supramolecular assemblies in the solid state. This analysis revels that the main contributions are provided by the $\mathrm{O} \cdots \mathrm{H}, \mathrm{H} \cdots \mathrm{H}$ and Co $\cdots \mathrm{O}$ interactions that represent $\sim 85 \%$ of the total contributions to the Hirshfeld surface. Pyrophosphate group show bent eclipsed conformation which was confirmed by IR spectroscopy. Its Thermal behaviour consists mainly of the loss of hydrazine moieties and water molecules leading thus to the formation of an anhydrous cobalt diphosphate. The condensed phosphate exhibits a promising catalytic activity in the oxidation and decomposition of methylene blue dye with hydrogen peroxide under ambient conditions only for 2 hours.

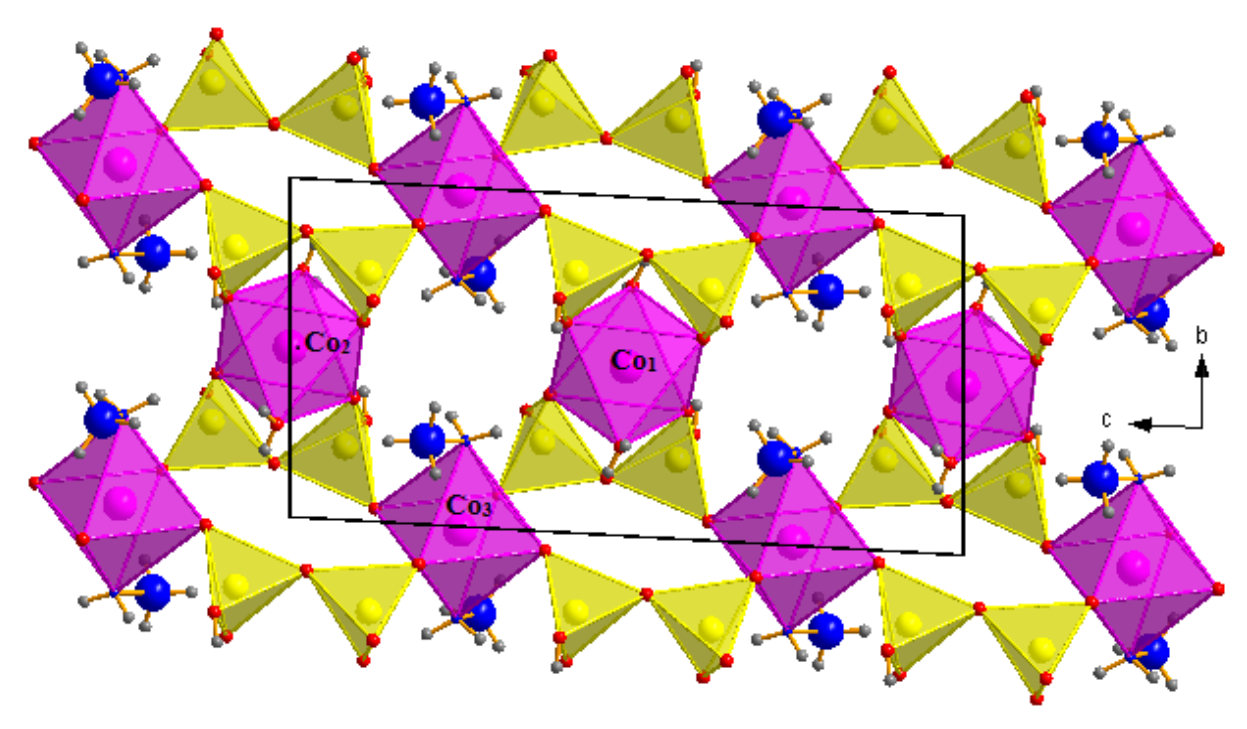

Figure 1: Polyhedral presentation of $\left[\left(\mathrm{H}_{2} \mathrm{O}\right)_{2} \mathrm{Co}_{2}\left(\mathrm{~N}_{2} \mathrm{H}_{5}\right)\left(\mathrm{HP}_{2} \mathrm{O}_{7}\right)_{2}\right]$ layer along [100] direction

Keywords: acid metallate pyrophosphate, slow evaporation method, crystal structure, catalytic activity 